\title{
Elimination of Chagas disease transmission: perspectives
}

\author{
João Carlos Pinto Dias \\ Instituto René Rachou-Fiocruz, Av. Augusto de Lima, 1715, 30190-002 Belo Horizonte, MG, Brasil
}

\begin{abstract}
One hundred years after its discovery by Carlos Chagas, American trypanosomiasis, or Chagas disease, remains an epidemiologic challenge. Neither a vaccine nor an ideal specific treatment is available for most chronic cases. Therefore, the current strategy for countering Chagas disease consists of preventive actions against the vector and transfusion-transmitted disease. Here, the present challenges, including congenital and oral transmission of Trypanosoma cruzi infections, as well as the future potential for Chagas disease elimination are discussed in light of the current epidemiological picture. Finally, a list of challenging open questions is presented about Chagas disease control, patient management, programme planning and priority definitions faced by researchers and politicians.
\end{abstract}

Key words: vector control - congenital transmission - transfusional transmission - oral transmission

A century after Carlos Chagas' original discovery, this is an opportune time for a discussion of state of the fight against Chagas disease (CD). The main tools and strategies for disease control became available between 1945-1970, but programme implementation was not prioritised until the 1980s (Dias \& Schofield 1999, WHO 2002). Since neither an effective vaccine nor an ideal specific treatment for most chronic cases is currently available, the basic strategy against $\mathrm{CD}$ still consists of preventive actions against the vector and transfusiontransmitted disease. The most effective tools and methods involve insecticide campaigns, housing improvement, health education and blood donor serological screening (Silveira 2000, Carlier et al. 2002, Dias \& Schofield 2004, Schmunis 2007). The impact of regular preventive actions against $\mathrm{CD}$ has been very high in those regions where sustainable programmes were implemented, as predicted by Emmanuel Dias, the pioneer of CD control (Dias 1957, Coura 1997, 2007). In parallel, the intensive rural-urban migration in all of Latin America additionally decreased transmission during the last few decades, as did the progressive modernisation of agriculture and cattle farming in the region (Dias \& Schofield 2004, Miles et al. 2004, Schmunis 2007). The good results obtained by control programmes in different areas and the clear positive cost-benefit relation became the "leitmotif" used by the scientific community to stimulate sanitation authorities and governments to expand national programmes in different countries (Schofield \& Dias 1991, Akhavan 2000, Dias 2002, Schmunis 2007). During the 1990s, the integration of CD control efforts across multiple countries occurred in different areas of Latin America, by means of an objective and intensive joint venture (the International Intergovernmental Initiatives) involving the scientific community, health authorities and the Pan American Health Organization (Dias et al.

Corresponding author: jcpdias@cpqrr.fiocruz.br

Received 13 April 2009

Accepted 16 June 2009
2002, Dias 2006b, Salvatella 2007). The first successful "initiative", launched in 1991, was implemented in the Southern Cone and resulted in a significant reduction of CD incidence in the region (Dias \& Coura 1997, Dias 2007, Salvatella 2007). Additionally, Chagas-related morbidity and the mortality also went down in Brazil as an effect of epidemiological cohort and possibly also due to the reduction of parasite reinfections and the absence of vector contamination in younger individuals (Dias 1982, 2006a, Prata 2001, Carlier et al. 2002).

In Latin America, from 1990-2006, some epidemiological indicators decreased following the implementation of objective control actions, as shown in a recent WHO workshop. More specifically, the current situation of the Regional Latin American Initiatives can be summarised as follows (Salvatella 2007): Uruguay, Chile and Brazil: interruption of main vector transmission across the entire country; Argentina, Paraguay and Bolivia: partial interruption; Guatemala, Honduras and El Salvador: Rhodnius prolixus eliminated in some areas; CA: different levels of Triatoma dimidiata control; Andean Countries Chagas Programs: in progress; Amazonian Surveillance System: in progress; México National Chagas Programme: in progress; non-endemic countries: a new initiative is being proposed to address the challenge of human migration and the possibility of transmission by means of congenital, blood transfusion or organ transplantation routes.

Based on these figures, the World Health Assembly 51.14 Resolution stated that the elimination of CD could be attained in 2010 by means of continuous control and necessary surveillance in the endemic areas (Salvatella 2007). Analysing this goal, a panel formed by experts from the Chagas Disease American Intergovernmental Initiatives understood that the concept of eradication was not applicable in terms of American trypanosomiasis and decided to clarify the following aspects (Dias et al. 2008).

$\mathrm{CD}$, an endemic infectious disease, was formerly a primitive enzootic phenomenon, which in Latin America suffered an evolution to a widespread anthropozoonosis. An ideal specific treatment in its chronic phase does not exist and an effective vaccine is still not available. 
Moreover, Trypanosoma cruzi still naturally circulates in widespread sylvatic ecotopes all over the American Continent; arguments for continent-wide control have not been made. For these reasons, American trypanosomiasis cannot be considered eradicable, since eradication means the definitive disappearance of the parasite. Nevertheless, the elimination of the transmission of CD represents an intermediate and pragmatic concept, to be understood as the absence of transmission (or of a determined vector species) in a defined geographical space, being dependent of the maintenance of continuous control and/or surveillance actions.

In parallel, a residual contingent of at least 12 million previously infected individuals remains living in endemic and non-endemic countries, creating the possibility for production of new cases by means of alternative mechanisms of $T$. cruzi transmission, mainly through congenital and transfusion routes.

In addition, the persistence of sylvatic enzootic foci has been increasingly involved in the eventual transmission of $\mathrm{CD}$ to humans by means of opportunistic dwelling invasion by adult triatomines, by the occasional human invasion of infested forests and, mainly, by the so-called oral transmission of human $\mathrm{CD}$, with about 100 new cases being reported annually in the last 10 years (Carlier et al. 2002, Dias et al. 2002, Miles et al. 2004).

Even so, during the last two decades, the transmission of human $\mathrm{CD}$ has been effectively controlled in several endemic areas by means of massive vector control efforts followed by continued surveillance and the regular serological screening of blood donors (Moraes Souza et al. 1997, Schmunis et al. 2001, WHO 2002, Pirad et al. 2005).

The prevention of parasite transmission to new generations, plus the intensive reduction of domestic triatomines in a region with control efforts, generated the pragmatic concept of elimination, which has a temporal and geographical meaning, since the control actions are maintained in a sustainable way (Salvatella 2007, Dias 2009).

In the particular case of introduced and restricted domestic triatomines (such as Triatoma infestans in several countries and R. prolixus in Central America and Mexico), the concept of elimination can also be applicable to such vector species (Silveira 2000, Salvatella 2007).

Thus, although American trypanosomiasis cannot be eradicated, an intensive and consistent reduction in human CD transmission has been observed in several endemic areas under regular vector and blood bank control. Even so, an epidemiologically important residual area of incidence and morbidity still exists (Dias 2006b). Since the theoretic and semantic distinction between CD eradication and elimination in reality does not exist, the main problem for scientists and governments remains in the sustainability of the control activities. From a political standpoint, it must be recognised that because CD affects mainly poor and socially marginalised populations, the main preventive actions and programmes will be necessarily carried out by the governmental, and so will depend on political decisions (Briceño-León 1990, Schmunis 2007, Dias et al. 2008).
Challenges and epidemiologic perspectives for the near future - Our concerns about $\mathrm{CD}$ in the coming years take into account both political and scientific processes, since sustainability of control efforts depends on political will and some difficulties, such as insecticide resistance must be surmounted (Dias \& Schofield 2004, Dias 2009). It is also very important to take into account that the social impact of the disease is still very high throughout the endemic area. According to several authors, for practical purposes CD must be considered a neglected disease, closely related to human poverty, programme instability, regional conflicts, lack of political priority, lack of minimum technical expertise and government corruption (Schmunis 2007, Dias 2009). From another angle, new epidemiological situations have been detected, such as oral transmission and domestic invasion by wild triatomines (Dias et al. 2002, Salvatella 2007). Other epidemiological situations may emerge, since the social and ecological context of this endemic and metaxenic disease is extremely complex (Dias \& Coura 1997, Miles 2004, Schmunis 2007). In particular, the themes of political priority and sustainability of control efforts are considered the most important in keeping an endemic area free of CD. In addition, more and new applied research is needed for improvement of control approaches, considering some particular conditions of disease control and management (Dias 2006b).

Naturally, because of the existing natural (sylvatic) foci of triatomines and a significant number of previously infected individuals, sporadic cases of acute disease and programme troubles can occur in the following specific situations (Dias \& Coura 1997, Carlier et al. 2002, Dias et al. 2008):

Congenital $C D$ - The most likely possibility is that it will progressively decrease following vector control in most endemic areas (Carlier et al. 2002, Dias 2006b). Progressively, the number of infected fertile women is going down due to the reduction of new cases in the youngest age groups and also the natural decrease in pregnancy rates in older age groups. For instance, in Bambui Town (a classic, hyper-endemic region in Brazil 60 years ago), the prevalence of $\mathrm{CD}$ in women from 15-40 years old decreased from $45 \%(1950 \mathrm{~s})$ to $11 \%$ (1968), then to $3.5 \%$ (1987) and then to less than $1 \%$ (2005). On the other hand, the pregnancy rate in higher age groups (30-40 years old) is significantly lower than in the young (15-25 years old) age group ( $5 \%$ and $>60.0 \%$, respectively), according to Dias (2006a) [Bambui was submitted to the pioneer desensitization campaign by Emmanuel Dias at the end of the 1950s and began regular entomological surveillance in 1974 (Dias 1957, 1982, 2006a)]. Notwithstanding, the occurrence of congenital cases must still be monitored in several countries over the next 20 or 30 years, chiefly in those where vector control programmes are only beginning or do not meet minimum sustainability requirements (Dias \& Schofield 2004, Salvatella 2007, Dias 2009).

Transfusion-transmitted $C D$ - The general scenario is quite similar to that for congenital transmission, but applied to infected blood donors (a progressive reduction of young blood donor candidates). Considering the pro- 
gressive decrease in infected blood donors as a mediumterm consequence of vector control, it is expected that the blood bank control efforts must persist for approximately another 20 years in endemic countries. For the next decade, a series of challenges and constraints must be addressed in the working agenda of health authorities and researchers. The key point will be the maintenance of donor control, in terms of cost benefit, as well as the desirable improvement of serological tests in terms of sensitivity and specificity. A new perspective for universal chemoprophylaxis is also a research goal (MoraesSouza et al. 1997, Schmunis et al. 2001, Pirard et al. 2005). Additionally, the regular and effective serological screening of donor candidates is being improved in most endemic countries, in parallel with awareness and also focal screening in non-endemic countries (Schmunis et al. 2001, Salvatella 2007). Nevertheless, considering that blood banks are still uncontrolled in some endemic and non-endemic areas, and that the sensitivity of screening tests is low even in some controlled areas, eventually a few acute cases could appear during the next 20 years (Dias et al. 2008). For this reason, febrile post-transfusional cases must be checked for acute $\mathrm{CD}$, mainly when the blood donor comes from an endemic country (Moraes Souza et al. 1997, Silveira 2000, WHO 2002).

Orally transmitted $C D$ - This is a totally unpredictable situation that has been detected in some particular areas (such as the Brazilian Amazon), chiefly in the last two decades. Several kinds of food (such as fresh fruit juices) have been suspected of carrying $T$. cruzi that probably originated from sylvatic triatomines that eventually invaded domestic and peridomestic areas. The result is periodic outbreaks of acute CD. The best approach to this situation seems to be rapid detection and consequent epidemiologic investigation of the case. For cases suspected of oral transmission, the other "classic" transmission mechanisms (vectorial, transfusional and congenital) must be ruled out (Dias \& Schofield 2004).

In some epidemiologically unusual areas and in those with inadequate control efforts, vector transmission may persist, requiring additional research and/or programme revision (Dias et al. 2002, 2008).

In areas in which control was effective, eventually the obtained success can lead to negligence or deactivation of programmes, chiefly when other health priorities (such as dengue fever) appear (Silveira 2000, Salvatella 2007, Dias 2009).

There is always the risk of programme errors when epidemiological data are inadequately obtained or are insufficient. This situation used to occur frequently in decentralised programmes, particularly when human resources were scarce and/or poorly prepared (WHO 2002, Dias 2009).

There is also a very common risk of programme weakening in decentralised systems as a consequence of the loss of human resources at the central and regional levels. In that case, the modern policy of "State Shortening" can be very harmful, because peripheral municipalities generally do not have the technical expertise to continue the control efforts by themselves. The municipalities have no tradition of vector control and epidemio- logical surveillance. In such circumstances, very strong central and sub-regional technical teams are required to accomplish the actions, motivation, qualification and regular supervision of the peripheral units (Schmunis 2007, Dias 2009).

At the same time, considering morbidity and mortality, several studies have indicated a reduction in the medical impact of CD in the last several million decades. The reasons for this seem to be complex and multifactorial, deserving careful analysis. The urbanisation of millions of infected individuals may be associated with better medical attention, reduction of physical efforts, interruption of exogenous reinfection and other possible causative parameters (Dias 1962, 2006a). Nevertheless, the existence of 12 million infected individuals will not permit a merely contemplative attitude on the part of health professionals and authorities over the coming decades. One of the more urgent tasks in the new millennium is simply the provision of adequate medical care to chagasic individuals, mainly for those suffering from chronic cardiopathy (Prata 2001, WHO 2002).

In terms of the future outlook, the next two decades will probably be characterised by the progressive reduction and focalisation of domestic vector populations, following predictable changes in sylvatic ecotopes (puzzle and concentration phenomena) and decreases in rural human populations. There will be a progressive reduction in infection levels in areas under regular control, but some foci will probably remain within pockets of poverty, isolation and poor political and sanitary infrastructure. New expansion areas on agricultural borders may occur, as observed in the Amazon Region (Silveira 2007). Urban foci and alternative means of transmission, for example, oral, may also appear in random and unexpected ways. A new clinical scenario is occurring right now among elder patients, involving complications to the disease due to the addition of other chronic-degenerative impairments, which are more relevant in higher age groups. A general lack of interest in investigating $\mathrm{CD}$ is anticipated in the whole region.

As a price of the present success and the decrease in disease visibility, as well as of the political and administrative inconsistency in the region, some predictable risks must be assumed (Dias 2002, 2006b): progressive weakening of national programmes and surveillance, as a consequence of other priorities and health system decentralisation; progressive loss of trained human resources because of failure to renew programmes, resource deviation, or a reduction in regular supervision and/or capability at central and regional levels etc.

Loss of epidemiological information - This question is critical for programme planning and priority definitions; (i) absence or weakness of the educational component, leading to weaker surveillance and community participation; (ii) several difficulties for the medical counter-reference of cases, chiefly when the primary health system is not equipped and trained to manage the disease; (iii) lack of basic pharmacological essentials for chagasic people, including not only specific antiparasitic drugs but also several drugs involved in the management of chronic manifestations, especially those 
of Chagas-associated heart disease; (iv) the pragmatic misunderstanding of isolated and marginal populations; (v) loss of research priority, mainly in terms of applied research and (vi) loss of consistency and priority in the university curricula.

In summary, the virtual elimination of $\mathrm{CD}$ can be considered an attainable goal, but we still are at risk. Addressing the following series of additional questions will be crucial in the near future (Dias 2006b, Dias et al. 2008): is it possible to maintain the current critical mass of research and service? If so, for how long? Is the occurrence of a new malaria-like situation possible for CD? How will the priority standards for National Programmes be maintained, considering the health system decentralisation, political weakness and decreases in priority? Who will be the main actors and what will be the central agenda for the next two decades? What have been the principal success and failure lessons from past control, health services and research efforts? What is the best legacy we can leave to the next generations of citizens, researchers and politicians?

In terms of political strategy, these points must remain in the agenda of the WHO and of the governments of endemic countries for the next two or three decades in order to maintain interest in and the priority of $\mathrm{CD}$ and its control. National and regional programmes must be adapted to the decentralisation of health systems. Efforts of new non-governmental partners, such as Mèdicins Sans Frontiéres, JICA, IDRC, ECLAT and others, are proving to be very effective and opportune for facing $C D$ in endemic and non-endemic countries. The recent institution of a global scientific network to address CD by the WHO Neglected Diseases Department is very timely.

The basic structure of this network involves the following goals (Albajar Viñas \& Dias 2009): to strengthen epidemiological surveillance and information systems (communities, vectors, cases and other factors relevant to transmission), to prevent transfusional and organ transplantation transmission of $T$. cruzi in endemic and non-endemic countries (policies and regulations), to achieve a consensus on diagnostic tests for screening and diagnosis of $T$. cruzi infections and to identify needed improvements, to expand prevention and control of congenital transmission and case management of congenital and non-congenital infections in endemic and non-endemic countries.

For the particular case of Latin America, it is very important to keep the Pan American Health Organization involved in the coordination of the regional initiatives (Dias et al. 2006a, Salvatella 2007).

Analysing the whole situation, the remaining central questions seem to be about political will, sustainable control programmes and technical expertise. Additional research is required to address some problems in improving control and some new epidemiological situations, as well as the unpredictable occurrence of oral transmission (Dias \& Schofield 1999, Schofield \& Dias 1991, Dias et al. 2002). A responsible attitude is required from the scientific community, which has always been involved with the most relevant decisions about CD knowledge and control (Coura 1997, Dias 2006b). A complete victory against $C D$ has not been achieved
TABLE

Changes in some epidemiological parameters following the transmission interruption of Chagas disease, 1990-2006

\begin{tabular}{lccc}
\hline Epidemiologic parameters & 1990 & 2000 & 2006 \\
\hline Annual deaths & $>45,000$ & 21,000 & 12,500 \\
Human cases of infection & 30 million & 18 million & 15 million \\
Annual incidence & 700,000 & 200,000 & 41,200 \\
Population under risk & 100 million & 40 million & 28 million \\
Distribution & 21 countries & 19 countries & 18 countries \\
\hline
\end{tabular}

Data from TDR/WHO, PAHO, WHO (reviewed in Salvatella 2007).

and much remains to be done. The greatest danger in the case of good news lies in premature celebration and the slackening of control measures. It also must be remembered that the decentralisation of health programmes across Latin America radically transformed classic control activities in municipal programmes. Another correlated problem arises from the usual political instability of local (municipal) governments, which places the sustainability of surveillance activities at risk. In terms of vector control, if epidemiological vigilance is prematurely relaxed, the consequences could be severe due the progressive re-establishment of active transmission foci, involving prior vector population recovery and/or housing invasion by secondary and sylvatic species (Dias et al. 2002, Dias 2009, unpublished observations).

Other biological and contextual situations may appear in the future of $\mathrm{CD}$ and its control. For example, an important and speculative question is whether the possible introduction of different $T$. cruzi groups to a given area, as a result of ecological and anthropic changes, may be promoting different patterns of morbidity (Prata 2001, Dias 2006a). From a sociological perspective, a very fundamental obstacle for overcoming the disease will be the so-called "sick house" (la casa enferma), so well described by Briceño León (1990): infested rural huts mean an isolated context of poverty, low political profile and very low quality of life. The sick house does not stimulate self-reliance, nor does it bring happiness. The same situation can be discussed in the case of ruralurban migration of chagasic people, in which the condition of the slum houses are quite similar to (or worse than) their original huts.

Finally, considering morbidity and mortality, several studies have indicated a reduction in the medical impact of the disease in the last few decades. The reasons for this seem to be complex and multi-factorial, deserving careful analysis. The urbanisation of millions of infected individuals can be associated with better medical attention, reduced physical efforts, interruption of exogenous reinfection and other possible causative parameters. Nevertheless, the existence of 12 million infected individuals will not permit a merely contemplative attitude on the part of health professionals and authorities over the coming decades. One of the more urgent tasks in the new millennium is simply the provision of adequate medical care to chagasic individuals, mainly for those suffering from chronic cardiopathy (Prata 2001, WHO 2002). 
Future - The progressive reduction of $\mathrm{CD}$ prevalence and morbidity is expected in endemic areas, correlated with control activities and with the mortality of previously infected individuals. As a consequence, the social and political visibility of the disease will decline, as will the priorities for control and research (Dias et al. 2002, Dias 2007). In conclusion, the virtual elimination of CD can be considered an attainable goal, but we remain at risk. Additional questions will be crucial in the near future, such as: Is it possible to maintain the current critical mass of research and service? If so, for how long? Is the occurrence of a new malaria-like situation possible for CD? How will the priority standards for National Programmes be maintained, considering the health system decentralisation, political weakness and decreases in priority? Who will be the main actors and what will be the central agenda for the next two decades? What have been the principal success and failure lessons from past control, health services and research efforts? What is the best legacy we can leave to the next generations of citizens, researchers and politicians?

Finally, it is germane to consider that the control of $\mathrm{CD}$ is achieving great success not just in epidemiological and scientific contexts. Briceño-León (1990), Dias et al. (2008) and Schmunis (2007) have observed that the corresponding activities, successes and difficulties are completely integrated in the scenario of retrieval and rescue possibilities of Latin America as a region that seeks its identity and its best political and social expression.

\section{REFERENCES}

Akhavan D 2000. Análise de custo-efetividade do programa de controle da doença de Chagas, Organização Panamericana da Saúde, Brasília, 271 pp.

Albajar-Viñas P, Dias JCP 2009. WHO global network for Chagas disease elimination. Rev Soc Bras Med Trop, in press.

Briceño-León R 1990. La casa enferma. Sociología de la enfermedad de Chagas, Capriles Ed., Caracas, 153 pp.

Carlier Y, Dias JCP, Luquetti AO, Hontebeyrie M, Torrico F, Truyens C 2002. Trypanosomiase Américaine ou maladie de Chagas. Enciclop Méd Chirurg 8: 505-520.

Coura JR 1997. Evolução dos conhecimentos. In JCP Dias, JR Coura (orgs.), Clínica e terapêutica da doença de Chagas. Um manual prático para o clínico geral, Editora Fiocruz, Rio de Janeiro, p. 33-66.

Coura JR 2007. Chagas disease: what is known and what is needed - A background article. Mem Inst Oswaldo Cruz 102 (Suppl. I): 113-122.

Dias E 1957. Profilaxia da doença de Chagas. Hospital 51: 485-498.

Dias E 1962. Os efeitos da superinfecção sobre a evolução da cardiopatia crônica chagásica. Rev Goiana Med 9 (Suppl.): 233-239.

Dias JCP 1982. Doença de Chagas em Bambuí, Minas Gerais, Brasil. Estudo clínico-epidemiológico a partir da fase aguda entre 1940 e 1982, PhD Thesis, Universidade Federal de Minas Gerais, Belo Horizonte, $376 \mathrm{pp}$.

Dias JCP 2002. Controle da doença de Chagas no Brasil. In AC Silveira (org.), El control de la enfermedad de Chagas en los paises del cono sur de América, Faculdade de Medicina do Triângulo Mineiro, Uberaba, p. 145-250.
Dias JCP 2006a. História Natural da Doença de Chagas. Estudo evolutivo e histórico em Bambuí, MG, Brasil. Monografia apresentada à Academia Mineira de Medicina, Belo Horizonte, $1480 \mathrm{pp}$.

Dias JCP 2006b. Chagas disease: successes and challenges. Editorial. Cad Saude Publica 22: 2021.

Dias JCP 2007. Southern Cone Initiative for the elimination of domestic populations of Triatoma infestans and the interruption of transfusional Chagas disease. Historical aspects, present situation and perspectives. Mem Inst Oswaldo Cruz 102 (Suppl. I): 11-18.

Dias JCP 2009. Sustentabilidade nas ações de controle da doença de Chagas no Brasil. Rev Soc Bras Med Trop, in press.

Dias JCP, Coura JR 1997. Epidemiologia. In JCP Dias, JR Coura (orgs.), Clínica e terapêutica da doença de Chagas. Um manual prático para o clínico geral, Editora Fiocruz, Rio de Janeiro, p. 33-66.

Dias JCP, Prata AR, Correia D 2008. Problems and perspectives for Chagas disease control: in search of a realistic analysis. Rev Soc Bras Med Trop 41: 193-196.

Dias JCP, Schofield CJ 1999. The evolution of Chagas disease (American trypanosomiasis) control after 90 years since Carlos Chagas discovery. Mem Inst Oswaldo Cruz 94 (Suppl. I): 103-121.

Dias JCP, Schofield CJ 2004. Control of Chagas disease. In I Maudlin, PH Holmes, MA Miles (orgs.), The trypanosomes, CABI Publishing, London, p. 547-564.

Dias JCP, Silveira AC, Schofield CJ 2002. The impact of Chagas disease control in Latin America: a review. Mem Inst Oswaldo Cruz 97: 603-612.

Miles MA, Yeo M, Gaunt MW 2004. Epidemiology of American trypanosomiasis. In I Maudlin, PH Holmes, MA Miles (orgs.), The trypanosomes, CABI Publishing, London, p. 243-251.

Moraes Souza H, Ramirez LE, Bordin JO 1997. Doença de Chagas transfusional: medidas de controle. In JCP Dias, JR Coura (orgs.), Clínica e terapêutica da doença de Chagas. Um manual prático para o clínico geral, Editora Fiocruz, Rio de Janeiro, p. 429-444.

Pirard M, Lihoshi N, Boelaert M, Basanta P, Lopez F, Van der Stuift P 2005. The validity of the serologic tests for Trypanosoma cruzi and the effectiveness of transfusional screening strategies in a hyperendeic region. Transfusion 45: 554-561.

Prata AR 2001. Clinical and epidemiological aspects of Chagas' disease. Lancet Inf Dis 1: 92-100.

Salvatella RA 2007. Achievements in controlling Chagas disease in Latin America, WHO, Geneva.

Schmunis GA 2007. Enfermedad de Chagas en un mundo global. In Fundación Mundo Sano (org.), La enfermedad de Chagas a la puerta de los 100 años del conocimiento de una endemia Americana ancestral, OPS/CD/426-06, Buenos Aires/Washington, p. 251-266.

Schmunis GA, Ziker F, Cruz JR, Cuchi P 2001. Safety of blood supply for infectious diseases in Latin American countries. Am J Trop Med Hyg 65: 924-930.

Schofield CJ, Dias JCP 1991. A cost-benefit analysis of Chagas disease control. Mem Inst Oswaldo Cruz 86: 285-295.

Silveira AC 2000. Profilaxia. In Z Brener, ZA Andrade, M BarralNeto (orgs.), Trypanosoma cruzi e doença de Chagas, 2nd ed., Guanabara Koogan Editora, Rio de Janeiro, p. 75-87.

Silveira AC 2007. Epidemiological and social determinants of Chagas disease and its control in the Amazon countries - Group discussion. Mem Inst Oswaldo Cruz 102 (Suppl. I): 71-74.

WHO - World Health Organization 2002. Control of Chagas Disease, WHO Technical series 905, Geneva, p. 96. 